\title{
Bioprocessos de Cocultivo Microbiano: avaliação tecnológica de Patentes
}

\author{
Microbial Co-Cultivation Bioprocesses: patents technological \\ assessment
}

\author{
Plínio Ribeiro Rodrigues ${ }^{1}$ \\ Tatiane Aparecida Barroso Silvério \\ Janice Izabel Druzian ${ }^{1}$ \\ ${ }^{1}$ Universidade Federal da Bahia, Salvador, BA, Brasil \\ ${ }^{2}$ Universidade Federal dos Vales do Jequitinhonha e Mucuri, Diamantina, MG, Brasil
}

\begin{abstract}
Resumo
Este estudo apresenta uma investigação de patentes para detecção de tendências tecnológicas e de mercado em bioprocessos e síntese de bioprodutos utilizando mais de uma cultura microbiana no meio de cultivo. Patentes de 1909 a 2017 foram coletadas e uma função sigmoide de dois estágios foi ajustada com sucesso $\left(\mathrm{R}^{2}=0,997\right)$ para modelar os documentos prospectados, contribuindo para melhor compreensão do estágio de desenvolvimento da técnica avaliada. Foram encontradas 632 patentes diferentes, publicadas principalmente nos Estados Unidos e China. O setor empresarial foi responsável pelo desenvolvimento de 50\% das invenções. O desenvolvimento da técnica está aumentando rapidamente após um período de crescimento lento (1909 a 1997), impulsionado, principalmente, por indústrias de produção de químicos de base biológica e biocombustíveis. O uso de microrganismos no cocultivo em bioprocessos e síntese de bioprodutos revelou alto potencial.
\end{abstract}

Palavras-chave: Cocultura. Bioprocessos. Modelagem.

\begin{abstract}
This study presents an investigation of patents data for detection of technological and market trends in bioprocesses and bio-products synthesis using more than one microbial culture in the cultivation medium. Patents from 1909 to 2017 were collected and a two-stage sigmoid function was successfully used $\left(R^{2}=0.997\right)$ to model the prospected documents, contributing for better understanding of the development stage of the technique assessed. There were found 632 different patents, published mainly in the United States and China. The business sector was responsible for the development of $50 \%$ of the technical inventions. The technique development is rising rapidly after a period of slow growth (1909 to 1997), pushed mainly by bio-based chemicals and biofuels industries. The use of microorganisms in co-cultivation in bioprocesses and bio-products synthesis revealed high potential for value generation in the coming decades, awakening great corporate interest.
\end{abstract}

Keywords: Co-culture. Bioprocesses. Modeling.

Área Tecnológica: Biotecnologia. Engenharia Química. 


\section{Introdução}

O uso de compostos químicos para suprir as atividades desenvolvidas na sociedade moderna é o pilar da indústria química mundial. Recentemente, os avanços no setor de síntese química foram fortemente alavancados e aprimorados com o aumento da escala de produção proporcionada por técnicas de engenharia, a fim de atender à crescente demanda do mercado (ROSSETTI; COMPAGNONI, 2016).

No entanto, o uso de produtos químicos sintéticos e os impactos de suas cadeias produtivas causam sérios danos ao meio ambiente; por exemplo, contaminações de solos e corpos aquáticos, e a emissão de gases de efeito estufa, que têm forte repercussão no meio ambiente e em mudanças climáticas (ENRÍQUEZ-DE-SALAMANCA et al., 2017; RAO SATHIAVELU; MYTHILI, 2016; VILLARREAL-CHIU; ARÉCHIGA-CARVAJAL, 2016). Assim, com o aumento das preocupações sobre a sustentabilidade dos recursos naturais do planeta e a fim de responder às novas demandas das indústrias químicas $e$ indústrias associadas, o uso de produtos biossintéticos torna-se uma estratégia de grande potencial (GARCÍA-SERNA; BARRERA; MONTIEL, 2007; CHARPENTIER, 2010).

Bioprocessos são métodos bioquímicos que utilizam substratos de origem biológica e/ou microrganismos para sintetizar ou modificar diversos produtos de interesse, como biocombustíveis, enzimas, biopolímeros, aditivos alimentares naturais, biofertilizantes, produtos farmacêuticos e aromatizantes (SERNA; BARRERA; MONTIEL, 2011; SINDHU et al., 2011; LIU, 2017). A fermentação é um dos bioprocessos mais antigos dominados pelo homem e pode ser realizada por meio de uma cultura pura de microrganismos ou por dois ou mais microrganismos em cocultura em um mesmo ambiente reacional (STANBURY; WHITAKER; HALL, 1995).

Embora nenhuma espécie viva isoladamente na natureza, os esforços para cultivar microrganismos para aplicações biotecnológicas geralmente se concentram na abordagem de uma única espécie de microrganismo. No entanto, a cocultura de microrganismos pode oferecer vários benefícios em relação à cultura pura, constituindo-se de uma estratégia promissora para permitir uma produção industrial mais sustentável e rentável e para garantir uma ampliação das aplicações microbiológicas no setor comercial (LIU, 2017).

Em termos gerais de produção, o cocultivo de comunidades microbianas é visto como uma estratégia alternativa e adicional à cultura pura tradicional. Fermentações com dois ou mais microrganismos oferecem benefícios sobre bioprocessos de cultura única, seja por comensalismo, neutralidade ou pela conversão de substrato em metabólito pelo primeiro microrganismo que é usado pelo segundo para a síntese dos produtos de interesse (STANBURY; WHITAKER; HALL, 1995; KONDO; KONDO, 1996; PADHI et al., 2016).

No cultivo em cocultura, o rendimento dos produtos e a taxa de crescimento microbiano podem ser maiores, estas culturas mistas são capazes de realizar transformações de múltiplas etapas que seriam impossíveis para um único microrganismo e, portanto, esse tipo de cultivo permite viabilizar fermentações com substratos mais baratos e impuros. Além disso, a possibilidade de produções simultâneas de múltiplos produtos em um único reator de fermentação é uma grande característica distintiva das tecnologias de cultura mista (CHEIRSILP; KITCHA; TORPEE, 2012; HUANG et al., 2017; YIN et al., 2016). 
Dada a escassez de dados na área, o presente trabalho teve como objetivo desenvolver uma avaliação tecnológica dos processos de cultivo em culturas simbióticas mistas. Documentos de patentes foram coletados, a fim de fornecer uma melhor compreensão do estágio de desenvolvimento da técnica e suas tendências gerais, fornecendo uma visão sistemicamente organizada e abrangente das informações recuperadas a partir desses documentos técnicos.

\section{Metodologia}

O presente estudo prospectivo foi realizado por meio da combinação de coleta de dados de patentes e modelagem matemática das informações obtidas.

\subsection{Coleta de Dados}

A busca por documentos de patentes foi realizada por códigos de Classificação Internacional de Patentes (CIP) na plataforma de dados da Classificação Internacional de Patentes (IPC), Espacenet. A avaliação dos códigos foi realizada pela seleção de todas as classificações compatíveis com o escopo de pesquisa em bioprocessos em cocultivo microbiano. A Tabela 1 exibe os códigos usados para recuperar os documentos de patentes. Pesquisas simples e truncadas, com combinação de todos os códigos, foram realizadas para obtenção da melhor seleção de dados.

Tabela 1 - Códigos Internacionais de Patentes usados para a coleta de documentos na base de dados Espacenet

$\begin{array}{cc}\text { Código DE CLASSIFICAÇão INTERNACIONAL } & \text { Definição } \\ \text { C12R1/00 } & \text { Processos usando microrganismos. } \\ \text { C12N1/00 } & \text { Microrganismos. } \\ \text { Y02P20/136 } & \begin{array}{c}\text { Tecnologias relacionadas à indústria } \\ \text { química de origem biológica. }\end{array} \\ \text { C12P39/00 } & \text { Processos envolvendo microrganismos de diferentes } \\ \text { gêneros no mesmo ambiente de produção. }\end{array}$

Fonte: Elaborado pelos autores deste artigo (2018)

A pesquisa realizada pelo código C12P39/00 ("Processos envolvendo microrganismos de diferentes gêneros no mesmo ambiente de produção"), no campo de buscas da plataforma Espacenet, foi escolhida como a melhor representante para o estudo de bioprocessos e síntese de bioprodutos utilizando mais de uma cultura de microrganismos. Os dados de patentes de 1909 a 2017 foram baixados no dia 21 de junho (2018) no formato XLS e tratados com as ferramentas disponíveis no software Microsoft Excel 2010. Documentos replicados foram excluídos do banco de dados para remoção de erros de tendência.

\subsection{Modelagem dos Dados}

Dados cumulativos do número de patentes em função do ano de publicação foram ajustados em vários modelos de crescimento sigmoide (Boltziv, Boltzmann, DoseResp, BiDoseResp e 
Richards), no software OriginPro 8.1- OriginLab, a fim de obter o melhor ajuste para detecção de tendências e a realização de previsões. Os modelos sigmoides são amplamente reconhecidos por sua adequação na adaptação e ajuste de dados de patentes (CANTÚ; ZAPATA, 2006; CARRILLO; GONZALEZ, 2002; MARINAKIS, 2012). O estágio de desenvolvimento da tecnologia prospectada foi analisado segundo o método publicado por Cantú e Zapata (2006).

\section{Resultados e Discussão}

Foram encontrados 632 documentos de patentes distintos para processos envolvendo microrganismos de diferentes gêneros no mesmo ambiente de produção (código C12P39/00) na plataforma de busca Espacenet, $71 \%$ dos quais publicados nos últimos 10 anos.

O Gráfico 1 mostra os 10 principais países em número de invenções. É possível observar os Estados Unidos da América (EUA) liderando o ranking de pedidos de patentes, com um total de $31,6 \%$ dos documentos protegidos. A China aparece em segundo lugar no número de patentes, com $24,5 \%$ das invenções protegidas (Gráfico 1 ).

Gráfico 1 - Os dez principais países em número de patentes de bioprocessos envolvendo microrganismos de diferentes gêneros no mesmo meio de produção no período de 1909 a 2017

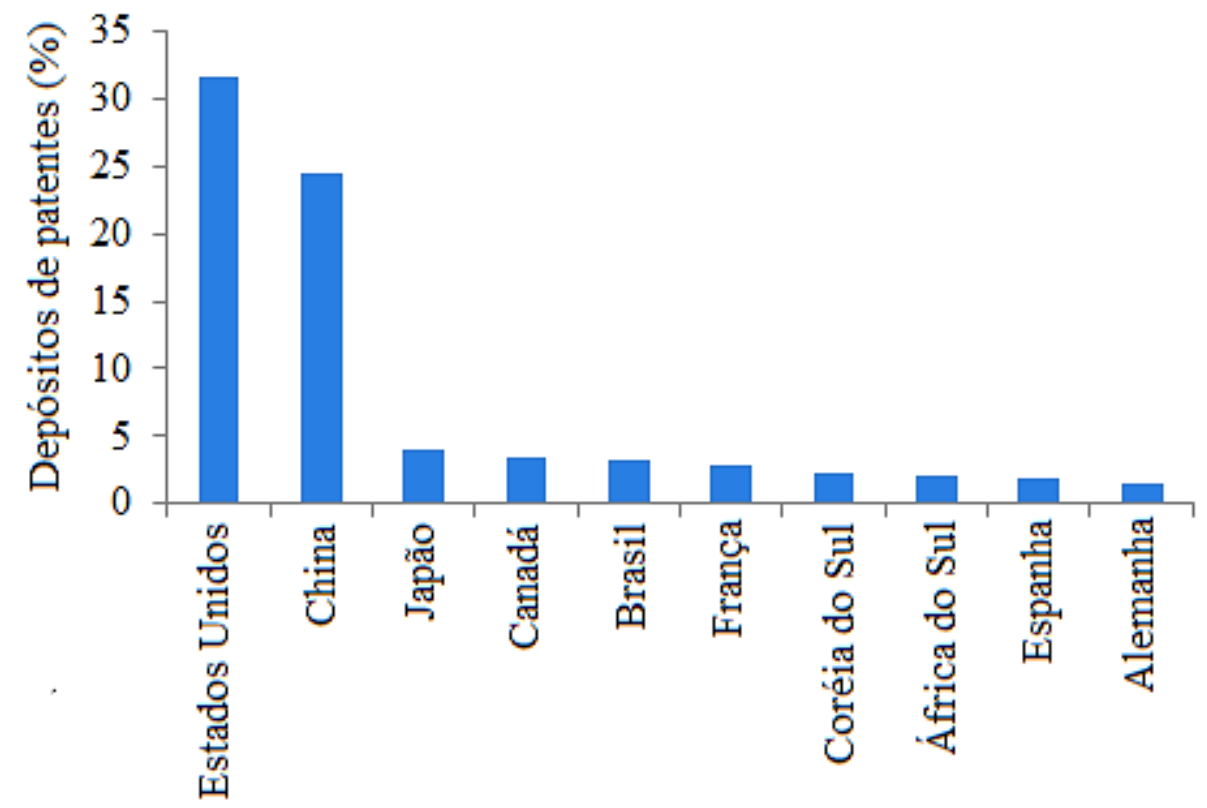

Fonte: Elaborado pelos autores deste artigo (2018)

Os Estados Unidos é o primeiro país em número de empresas de biotecnologia no mundo, com um total de aproximadamente 11.554 empresas, das quais $68,6 \%$ são de pequeno porte, com 50 ou menos empregados. Além disso, somente em 2014, o setor de pesquisa e desenvolvimento do país fez um investimento de US\$ 38,565 bilhões em biotecnologia, de acordo com publicação da OECD (2015).

Tal influxo de capital é justificado pela crescente demanda por produtos biotecnológicos em todo o mundo, que têm sido vistos como uma alternativa ao desenvolvimento industrial de forma mais limpa e sustentável, dado o aumento da conscientização dos consumidores e, 
consequentemente, das empresas, acerca dos impactos antrópicos prejudiciais aos ambientes naturais (MONCADA; ARISTIZÁBAL; CARDONA, 2016).

A China é o segundo país em inovações em bioprocessos e bioprodutos relacionados ao cultivo misto de microrganismos, a estrutura econômica chinesa foi largamente aprimorada e desenvolvida nos últimos anos, sinalizando uma perspectiva de crescimento mais estável à medida que o país se destaca como um dos principais produtores de ciência e tecnologia (GRUEBER; STUDT, 2013).

Curiosamente, após um desenvolvimento altamente intensivo e em larga escala por mais de três décadas, as indústrias tradicionais chinesas atingiram a saturação, mas ainda há abundância de oportunidades de investimento em infraestrutura, novos modelos de negócios e inovação tecnológica no país (ZHANG et al., 2016; NSB, 2016).

O Brasil marca a quinta posição em número de patentes envolvendo processos e produtos em cocultivo de microrganismos; com 3,16\% de todas as patentes depositadas (1909 a 2017). O país tem um grande potencial de desenvolvimento no setor de biotecnologia devido à grande diversidade de matérias-primas, ampla biodiversidade de microrganismos e um crescente mercado consumidor, mas ainda enfrenta grandes desafios de ordem política e estrutural que parecem bloquear um avanço mais pronunciado neste setor (COUTINHO; BOMTEMPO, 2011; SPAROVEK et al., 2016).

O Gráfico 2 apresenta a evolução anual do número de patentes no âmbito de avaliação deste trabalho no período de 1909 a 2017. É possível notar a presença de oscilações de publicações de patentes ao longo do intervalo avaliado, com tendência geral de aumento, indicando um status de desenvolvimento ativo para a tecnologia estudada.

Gráfico 2 - Número de patentes de bioprocessos envolvendo microrganismos de diferentes gêneros no mesmo ambiente de produção publicadas entre 1909 e 2017

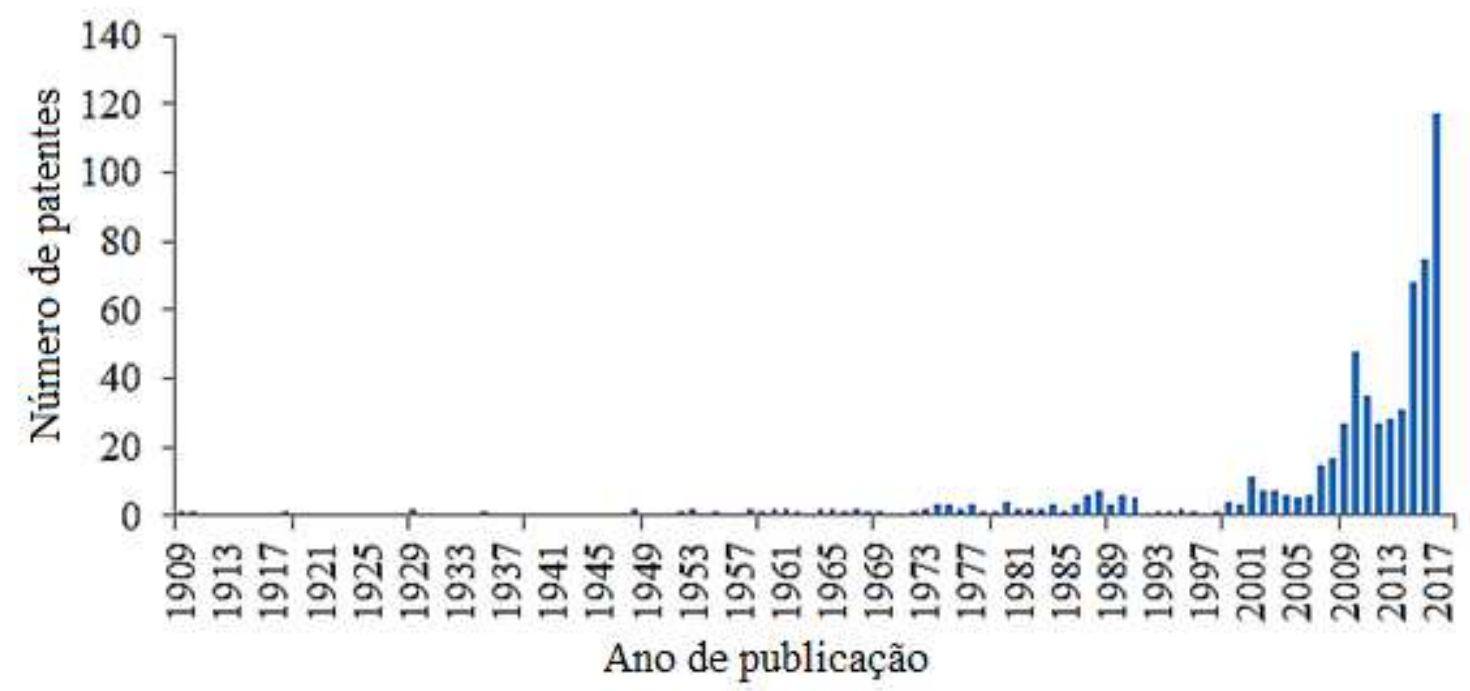

Fonte: Elaborado pelos autores deste artigo (2018)

Entre os anos de 1909 e 1997, o desenvolvimento tecnológico de bioprocessos e bioprodutos relacionados ao cocultivo de diferentes microrganismos apresentou uma tendência quase constante, com um baixo número médio de patentes, refletindo um desenvolvimento inventivo apático no cenário mundial (Figura 2). Esse comportamento pode estar relacionado aos 
desafios técnicos da tecnologia de culturas mistas. De acordo com Hesseltine (1992), o estudo científico de processos de cultivo microbiano é mais complexo de ser conduzido se mais de um microrganismo estiver envolvido; contaminações no processo são mais difíceis de detectar, identificar e controlar e a definição do equilíbrio ótimo entre os microrganismos em cultivo é mais complicado devido às interações entre eles.

Depois de 1997, no entanto, um grande aumento nas publicações de patentes é notado. Paralelamente, percebe-se também o desenvolvimento de tecnologias disruptivas nas áreas de biologia molecular, genômica, embriologia e computação, que começaram na década de 1980 e impulsionaram o avanço da indústria de biotecnologia nos anos 1990 e nos anos 2000 (BOWERS; ALLRED, 1995; HUNKAPILLER, 1991; COLTON, 1995; WAGNERA; ALPERAB, 2016). Portanto, é muito provável que esses avanços possam ter ecoado na pesquisa de bioprocessos e bioprodutos com uso de mais de uma cultura de microrganismos, juntamente à intensificação do financiamento para pesquisa e desenvolvimento tecnológico percebido nas últimas décadas, aumentando as publicações de patentes (OECD, 2015).

De maneira a identificar o estágio de desenvolvimento da tecnologia avaliada e fazer previsões mais robustas, o método sigmoide foi aplicado aos dados de distribuição cumulativa do número de patentes. Os dados de ajuste para os modelos estudados estão apresentados pela Tabela 2. Esse método é uma ferramenta útil para a produção de resultados preditivos em prospecção de patentes, dada a sua boa adequação na modelagem do comportamento $e$ tendências deste tipo de dados (CARRILLO; GONZALEZ, 2002).

Tabela 2 - Ajuste do número acumulado de patentes de bioprocessos e bioprodutos relacionados ao cultivo misto de microrganismos em função do ano de publicação em modelos de crescimento sigmoide

\begin{tabular}{cccc} 
Modelo & \multicolumn{2}{c}{ ANOVA } & $\mathbf{R}^{2}$ \\
\hline Boltziv & F & P & \\
DoseResp & 45,36 & $<0,01$ & 0,489 \\
BiDoseResp & 1064,61 & $<0,01$ & 0,967 \\
Boltzmann & 7588,53 & $<0,01$ & 0,997 \\
Richards & 1064,51 & $<0,01$ & 0,967 \\
\hline
\end{tabular}

Fonte: Elaborado pelos autores deste artigo (2018)

Como pode ser visto na Tabela 2, o modelo que obteve o melhor ajuste foi BiDoseResp $\left(\mathrm{R}^{2}=0,9974\right)$ (ANOVA: $\mathrm{F}=7588,53 ; \mathrm{p}<0,01$ ), que exibe comportamento sigmoide duplo; representado pela Equação 1.

$$
\mathrm{y}=\mathrm{A} 1+(\mathrm{A} 2-\mathrm{A} 1)\left[\frac{\mathrm{B}}{1+10^{(\mathrm{C}-\mathrm{x}) \mathrm{hn}}}+\frac{1-\mathrm{B}}{1+10^{(\mathrm{D}-\mathrm{x}) \mathrm{hz}}}\right]
$$

Para a qual; $y=$ número cumulativo de patentes, $\mathrm{A} 1=$ número inicial de patentes, $\mathrm{A} 2=$ número final de patentes, $\mathrm{B}=$ proporção, $\mathrm{C}=$ primeira mediana, $\mathrm{D}=$ segunda mediana, $\mathrm{h} 1$ $=$ primeiro coeficiente de inclinação e h2 = segundo coeficiente de inclinação. 
Segundo Cantú e Zapata (2006), diferentes estágios de desenvolvimento tecnológico podem ser identificados nas curvas de ajuste sigmoide para dados cumulativos de publicações de patentes, delimitados por pontos específicos em seu crescimento, como mostrado no Gráfico 3 (b). Em termos de desenvolvimento, uma tecnologia pode ser classificada como emergente, crescente, de ponta, madura ou em declínio. Portanto, o ajuste de dados de patentes para bioprocessos e bioprodutos relacionados a microrganismos de diferentes gêneros no mesmo ambiente produtivo revela a presença de duas fases (duplo sigmoide) de desenvolvimento técnico, o que pode ser notado por meio do Gráfico 3 (a).

A primeira fase apresenta início e declínio aproximados nos anos de 1909 e 1997, respectivamente. A segunda fase tecnológica ainda está em andamento (Gráfico 3-a), aproximando-se da região característica da onda tecnológica mais forte (região de crescimento do desenvolvimento). Os valores das variáveis C e D (medianas nas curvas sigmoides), mostrados no gráfico, destacam os períodos onde as fases tecnológicas alcançam os estágios de desenvolvimento de ponta (região onde a taxa de crescimento dos documentos de invenção é maior), alcançada no ano de 1982 para a primeira fase e prevista para o final de 2047 na segunda fase.

O coeficiente angular da inclinação da segunda sigmoide é maior ( $\mathrm{h} 2=0,084)$ do que o observado para a primeira ( $\mathrm{h} 1=0,041)$, indicando um desenvolvimento inventivo mais acelerado na segunda fase (fase atual). Esses dados estão de acordo com o incremento nos investimentos em pesquisa e desenvolvimento técnico e os avanços das técnicas de biotecnologia experimentadas mundialmente nas últimas décadas, encurtando o período necessário para que a tecnologia atinja sua maturidade (LIU, 2017; OECD, 2015; MONCADA; ARISTIZÁBAL; CARDONA, 2016). A partir do modelo gerado também pode-se prever que a maturidade da segunda fase técnica será atingida por volta do ano de 2057 com declínio a partir de, aproximadamente, em 2070.

Gráfico 3 - (a) Ajuste sigmoidal de dois estágios (BiDoseResp) para o número cumulativo de patentes de bioprocessos envolvendo culturas mistas de microrganismos no mesmo ambiente, publicadas entre 1909 e 2017 e (b) estágios de desenvolvimento tecnológico

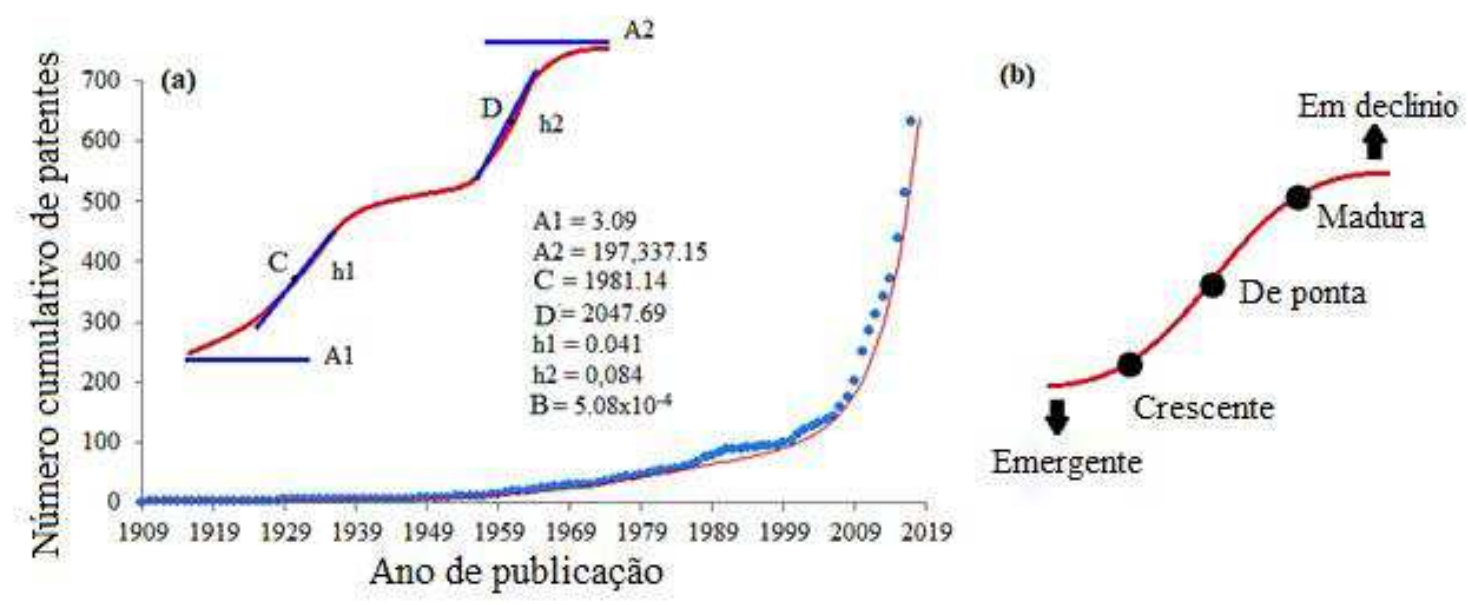

Fonte: Elaborado pelos autores deste artigo (2018)

Espera-se que o forte aumento projetado do mercado consumidor mundial nas próximas décadas, desencadeado pelo aumento da população humana (UN, 2015), exerça grande pressão sobre os investimentos em inovação, especialmente nos setores de biocombustíveis, produtos farmacêuticos, alimentos e biomateriais. 
A tecnologia de cocultura, associada aos avanços da engenharia genética, possivelmente desempenhará um papel significativo no suprimento dessa demanda, dado seu grau de desenvolvimento projetado para os próximos anos. Espera-se ainda que o número de patentes de processos envolvendo culturas mistas de microrganismos atinja 194.737 contagens até 2047, de acordo com a predição do ajuste sigmoide.

O Gráfico 4 fornece informações sobre a responsabilidade de desenvolvimento (depositantes) dos registros de propriedade intelectual, distribuídos entre empresas, pessoas físicas (inventores independentes ou não) e instituições de pesquisa e educação. Com base nesses dados, é possível observar que, no âmbito desta prospecção, o setor de maior destaque em pedidos de patentes é o empresarial, responsável por $50 \%$ dos registros, seguido pelas instituições de pesquisa e ensino, que detêm $25 \%$ dos registros de patentes, e, por fim, pesquisadores como pessoa física, com $13 \%$ dos depósitos de invenções.

Este estudo demonstra um grande interesse corporativo em processos biotecnológicos com aplicação de cocultura microbiana, em comparação com os outros setores observados (instituições de pesquisa e pessoas físicas), o que possivelmente se deve ao potencial dessa tecnologia de produção em elevar o rendimento da biossíntese comercial e consequentemente, aumentar a receita das empresas (NAI; MEYER, 2018).

Também é possível observar (Gráfico 4) uma rede de colaborações entre empresas, pessoas físicas e instituições de pesquisa/educação, que são mais abundantes entre empresas e pessoas físicas, o que confirma uma certa extensão de intercomunicação do conhecimento entre os setores da sociedade estudados em relação à técnica em estudo.

Parcerias entre empresas e instituições de pesquisa/educação foram as mais escassas (correspondendo a apenas 3\% das patentes publicadas), revelando um ponto fraco no desenvolvimento de bioprocessos com uso de culturas microbianas mistas. Dado que se reconhece que o envolvimento direto do setor empresarial nas atividades das instituições de pesquisa pode orientar as ações destas de forma mais eficiente para as necessidades da sociedade e para os desafios industriais, trazendo experiência, prática e técnica para apoiar a transferência de conhecimento (EUROPIAN COMISSION, 2007).

Gráfico 4 - Detentores (depositantes) dos documentos de patentes de bioprocessos envolvendo culturas mistas de microorganismos publicados mundialmente de 1909 a 2017

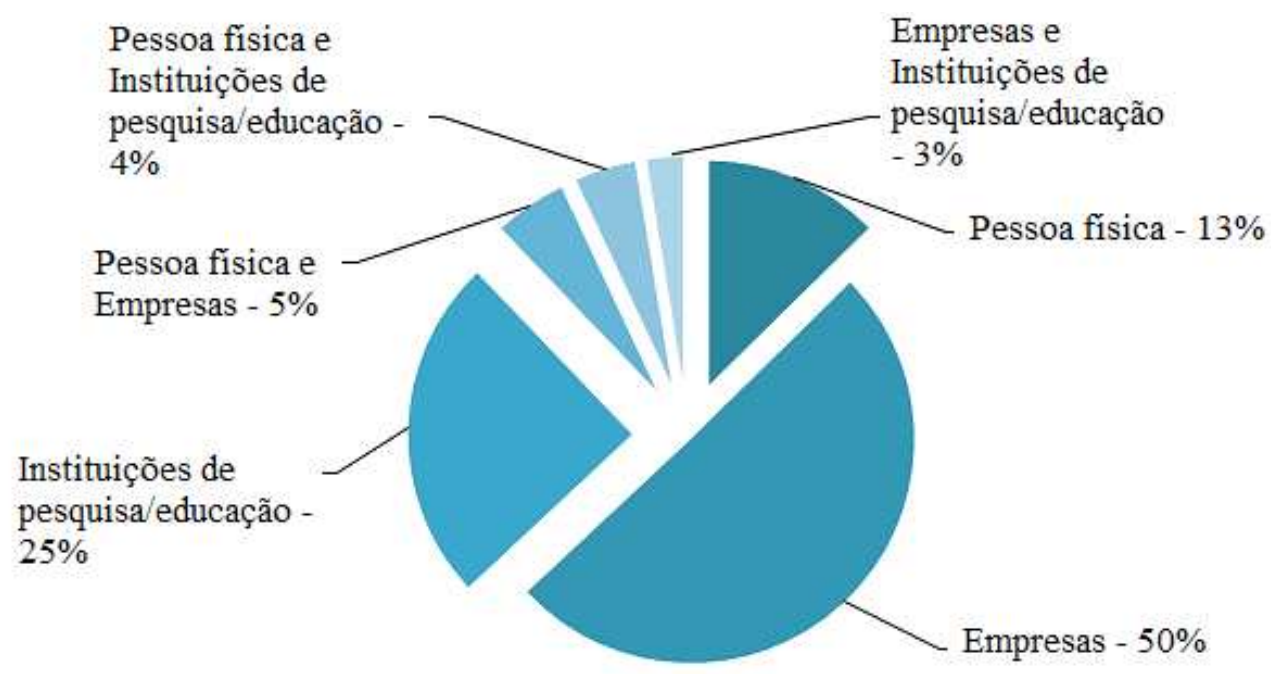

Fonte: Elaborado pelos autores deste artigo (2018) 
O Gráfico 5 mostra os principais campos de aplicação relacionados ao conteúdo das patentes de tecnologias de cocultura microbiana, depositadas entre os anos de 1909 e 2017. A maioria dos registros de invenção estão relacionados a campos de desenvolvimento de produtos químicos, combustíveis, detoxificação (remediação), alimentos/rações, polímeros e enzimas, nos mais diversos aspectos e abordagens.

A maioria das invenções patenteadas envolve a produção de compostos químicos ( 29,6\%), que também engloba a síntese de produtos de uso farmacêutico e terapêutico. $\mathrm{O}$ desenvolvimento de combustíveis ocupou o segundo lugar em depósitos de patentes, com foco principal na produção de bioetanol lignocelulósico e biohidrogênio, trazendo abordagens para resolver os desafios apresentados por estas tecnologias.

As invenções relativas à produção de alimentos/rações (incluindo aditivos alimentares) e a processos e alternativas de detoxificação (incluindo tratamentos para efluentes contaminados e eliminação de poluentes nos mais diversos ambientes) representaram aproximadamente $14,2 \%$ e $15,0 \%$ dos documentos protegidos, nesta ordem.

O desenvolvimento de tecnologias inventivas nas áreas de polímeros e enzimas também foi significativo entre as aplicações de destino do uso de bioprocessos envolvendo culturas mistas de microrganismos em um mesmo ambiente reacional.

Gráfico 5 - Campos de aplicação de patentes referentes a bioprocessos e bioprodutos envolvendo o uso de culturas mistas de microrganismos publicadas mundialmente de 1909 a 2017

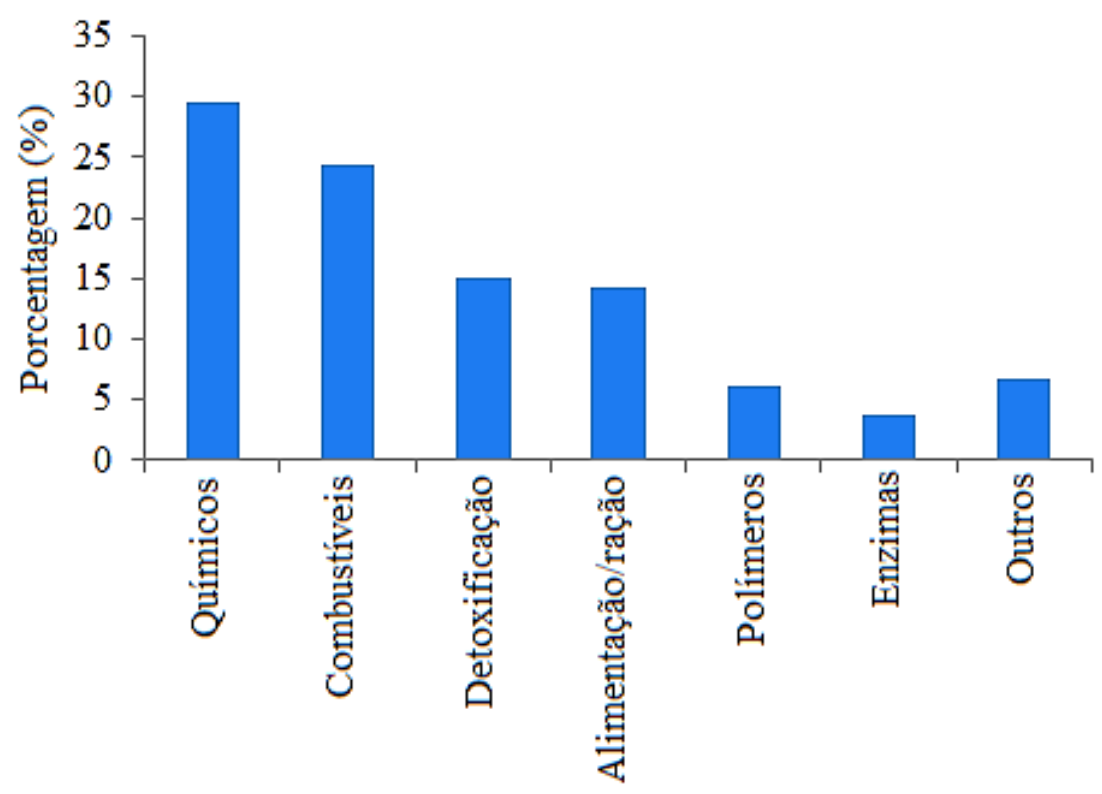

Fonte: Elaborado pelos autores deste artigo (2018)

Estes dados (Gráfico 5), junto aos dados dos Gráficos 2 e 3 (a), mostram que a aplicação da tecnologia de cocultivo microbiano estudada neste trabalho é uma ferramenta cada vez mais utilizada para abordar as principais questões da indústria mundial moderna de uma maneira mais limpa e sustentável; como a síntese de produtos químicos bioderivados e biocombustíveis, estratégias de recuperação ambiental, oferta para a demanda de alimentos/ração, e substituição de polímeros à base de petróleo por materiais biodegradáveis. 


\section{Considerações Finais}

O esforço tecnológico para conduzir cultivos de múltiplos microrganismos em um mesmo meio para a produção de produtos comercialmente valiosos vem ganhando força ao longo dos anos, liderado principalmente pelos campos de produtos químicos bioderivados, biocombustíveis, detoxificação de ambientes contaminados, produção de alimentos/rações, biopolímeros e enzimas. A modelagem sigmoide dos dados de patentes revelou a presença de duas fases no desenvolvimento da tecnologia, que está atingindo o maior nível de desenvolvimento de inovação de sua fase atual. A maioria dos documentos de patentes relativos à exploração de coculturas microbianas foi desenvolvida nos Estados Unidos e liderada pelo setor empresarial, revelando grande interesse corporativo pelas aplicações comerciais dessa tecnologia de cultivo. Em última análise, a técnica estudada apresenta um grande potencial de geração de valor para as próximas décadas, contribuindo para abordar as principais questões da indústria mundial moderna de uma maneira mais limpa e sustentável.

\section{Referências}

BOWERS, D. F.; ALLRED, J. B. Advances in molecular biology: Implications for the future of clinical nutrition practice. Journal of the American Dietetic Association, [S.l.], v. 95, n. 1, p. 53-59, 1995.

CANTÚ, S. O.; ZAPATA, A. R. P. ¿Qué es la Gestión de la Innovación y la Tecnología (GInnT)?

Journal of Technology Management \& Innovation, [S.I.], v. 1, n. 2, p. 64-82, 2006.

CARRILlO, M.; GONZALEZ, J. M. A. New Approach to Modelling Sigmoidal Curves.

Technological Forecasting and Social Change, [S.I.], v. 69, n. 3, p. 233-241, 2002.

CHARPENTIER, J. C. Among the trends for a modern chemical engineering, the third paradigm: the time and length multiscale approach as an efficient tool for process intensification and product design and engineering. Chemical Engineering Research and Design, [S.I.], v. 88, n. 3, p. 248-254, 2010.

CHEIRSILP, B.; KITCHA, S.; TORPEE, S. Co-culture of an oleaginous yeast Rhodotorula glutinis and a microalga Chlorella vulgaris for biomass and lipid production using pure and crude glycerol as a sole carbon source. Annals of Microbiology, [S.I.], v. 62, n. 3, p. 987-993, 2012.

COLTON, C. K. Implantable biohybrid artificial organs. Cell Transplantation, [S.I.], v. 4, n. 4, p. 415-436, 1995.

COUTINHO, P.; BOMTEMPO, J. V. Roadmap Tecnológico em Matérias-Primas Renováveis: uma Base para a Construção de Políticas e Estratégias no Brasil. Química Nova, [S.l.], v. 34, n. 5, p. 910-916, 2011.

ENRÍQUEZ-DE-SALAMANCA, A. et al. Environmental impacts of climate change adaptation. Environmental Impact Assessment Review, [S.1.], v. 64, p. 87-96, 2017.

ESPACENET. [Base de dados - Internet]. European Patent Office. 2018. Disponível em: https:// worldwide.espacenet.com/. Acesso em: 28 jun. 2018. 
EUROPIAN COMISSION. Improving knowledge transfer between research institutions and industry across Europe: embracing open innovation. Luxembourg: Office for Official Publications of the European Communities 2007. 36 p.

GARCÍA-SERNA, J.; PEREZ-BARRIGÓN, L.; COCERO, M. J. New trends for design towards sustainability in chemical engineering. Chemical Engineering Journal, [S.I.], v. 133, n. 1-3, p. 7-30, 2007.

GRUEBER, M.; STUDT, T. 2014 Global R\&D Funding Forecast. Battelle, Columbus, 2013.

HESSELTINE, C. W. Mixed-Culture Fermentations. In: RUSKIN, F. R. (ed.). Applications of biotechnology to traditional fermented foods. Washington: National Academy Press, 1992. p. 52-57.

HUANG, L. et al. Enhanced polyhydroxyalkanoate production by mixed microbial culture with extended cultivation strategy. Bioresource Technology, [S.I.], v. 241, p. 802-811, 2017.

HUNKAPILLER, M. W. Advances in DNA sequencing technology. Current Opinion in Genetics \& Development, [S.I.], v. 1, n. 1, p. 88-92, 1991.

KONDO, T.; KONDO, M. Efficient production of acetic acid from glucose in a mixed culture of Zymomonas mobilis and Acetobacter sp. Journal of Fermentation and Bioengineering, [S.1.], v. 81, n. 1, p. 42-46, 1996.

LIU, S. Bioprocess Engineering: Kinetics, Sustainability, and Reactor Design. New York: Elsevier, 2017.

MARINAKIS, Y. D. Forecasting technology diffusion with the Richards model. Technological Forecasting and Social Change, [S.1.], v. 79, n. 1, p. 172-179, 2012.

MONCADA, J.; ARISTIZÁBAL, V.; CARDONA, C. A. Design strategies for sustainable biorefineries. Biochemical Engineering Journal, [S.l.], v. 116, p. 122-134, 2016.

NAI, C.; MEYER, V. From Axenic to Mixed Cultures: Technological Advances Accelerating a Paradigm Shift in Microbiology. Trends in Microbiology, [S.l.], v. 26, n. 6, p. 538-554, 2018.

NSB - NATIONAL SCIENCE BOARD. Science and Engineering Indicators 2016. National Science Foundation, Arlington, 2016.

OECD - ORGANISATION FOR ECONOMIC CO-OPERATION AND DEVELOPMENT.

Key biotechnology indicators. [2015]. Disponivel em: http://www.oecd.org/sti/inno/ keybiotechnologyindicators.htm. Acesso em: 23 jul. 2018.

PADHI, S. et al. ITS2 RNA secondary structure analysis reveals close affinity between endophytic and pathogenic fungi: a case study in Fusarium species. Annals of Microbiology, [S.l.], v. 66, n. 2, p. 625-633, 2016.

RAO, A.; SATHIAVELU, A.; MYTHILI, S.; Genetic engineering in biobutanol production and tolerance. Brazilian Archives of Biology and Technology, [S.l.], v. 59, p. 1-14, 2016.

ROSSETTI, I. E.; COMPAGNONI, M. Chemical reaction engineering, process design and scale-up issues at the frontier of synthesis: Flow chemistry. Chemical Engineering Journal, [S.l.], v. 296, p. 56-70, 2016.

SERNA, F.; BARRERA, L.; MONTIEL, H. Impacto social y económico en el uso de biocombustibles. Journal of Technology Management \& Innovation, [S.1.], v. 6, n. 1, p. 100-114, 2011. 
SINDHU, R. et al. Production and characterization of poly-3-hydroxybutyrate from crude glycerol by Bacillus sphaericus NII 0838 and improving its thermal properties by blending with other polymers.

Brazilian Archives of Biology and Technology, [S.I.], v. 54, n. 4, p. 783-794, 2011.

SPAROVEK, G. et al. Sustainable bioproducts in Brazil: disputes and agreements on a common ground agenda for agriculture and nature protection. Biofuels, Bioproducts and Biorefining, [S.l.], v. 10, p. 204-221, 2016.

STANBURY, P. F.; WHITAKER, A.; HALL, S. J. Principles of Fermatation Tecnology. Burlington: Butterworth-Heinemann, 1995.

UN - UNITED NATIONS. Revision of World Population Prospects, UN, 2015. Disponível em: https://esa.un.org/unpd/wpp/. Acesso em: 10 abr. 2018.

VILLARREAL-CHIU, J. F; ARÉCHIGA-CARVAJAL, E. T. Biodegradation kinetic rates of dieselcontaminated sandy soil samples by two different microbial consortia. Annals of Microbiology, [S.I.], v. 66, n. 1, p. 197-206, 2016.

WAGNERA, J. M.; ALPERAB, H. S. Synthetic biology and molecular genetics in non-conventional yeasts: Current tools and future advances. Fungal Genetics and Biology, [S.l.], v. 89, p. 126-136, 2016.

YIN, Q. et al. Enhanced methane production in an anaerobic digestion and microbial electrolysis cell coupled system with co-cultivation of Geobacter and Methanosarcina. Journal of Environmental Sciences, [S.l.], v. 42, p. 210-214, 2016.

ZHANG, H. et al. Where will China's real estate market go under the economy's new normal? Cities, [S.I.], v. 55, p. 42-48, 2016.

\title{
Sobre os Autores
}

\author{
Plínio Ribeiro Rodrigues \\ E-mail: plinioeng@hotmail.com \\ Química. \\ Endereço profissional: Rua Aristides Novis, n. 2, Federação. Salvador, BA. CEP: 40210-630.
}

\section{Tatiane Aparecida Barroso Silvério}

E-mail: tatibasilverio@gmail.com

Bacharel em Engenharia Química.

Endereço profissional: Alto da Jacuba, n 5.000, Rodovia MGT 367, Km 583, Diamantina, MG. CEP: 39100-000.

\section{Janice Izabel Druzian}

E-mail: janicedruzian@hotmail.com

Bacharel em Química Industrial, Mestre em Química e Doutora em Ciência de Alimentos. Professora Associada IV da UFBA.

Endereço profissional: Rua Aristides Novis, n. 2, Federação, Salvador, BA. CEP: 40210-630. 